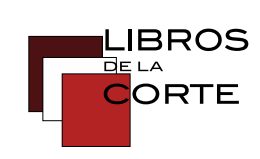

\title{
«CON POBREZA PRETENDÍ»: LA CABALLERÍA TRONADA Y LA FIGURA DEL PRETENDIENTE EN LA CORTE SEGÚN CERVANTES, GUILLÉN DE CASTRO Y CRISTÓBAL SUÁREZ DE FIGUEROA
}

\author{
Héctor Brioso Santos \\ (Universidad de Alcalá) \\ hbrioso@hotmail.com
}

\section{RESUMEN}

La tensión entre la inercia social estamental y la nueva movilidad propia de la economía dineraria es palmaria en la literatura del Siglo de Oro español. La hidalguía estaba en entredicho, devaluada y empobrecida, según muestran Cervantes y otros. En ese contexto, Guillén de Castro presenta, en El pretender con pobreza, el conflicto, un tanto autobiográfico, del exsoldado linajudo y honrado que espera ser valorado, al estilo tradicional, por sus merecimientos, y no por su pobre apariencia y escaso peculio, como sucederá en la era del boato y la cortesanía. En realidad, la solución de esa pieza será harto inmovilista y conservadora, puesto que el hidalgo protagonista logrará restaurar su crédito social y recibirá la debida recompensa de los poderosos. Según Castro, la alta nobleza debería rescatar por solidaridad estamental a los caballeros dignos y valerosos, y la corona tendría que redimir a esa caballería depauperada de su triste destino. Cristóbal Suárez de Figueroa, mucho más pesimista, ni siquiera toma en consideración ese camino en El pasajero, sino que expresa una dura crítica a la nobleza y al poder mal ejercido. El primer autor se interesa por la vertiente social y el segundo más por la política.

PALABRAS CLAVE: Nobleza, hidalguía, movilidad social, pretendiente, Cervantes, Guillén de Castro, El pretender con pobreza, Cristóbal Suárez de Figueroa, El pasajero.

\section{«CON POBREZA PRETENDÍ»: IMPOVERISHED KNIGHTHOOD AND THE CHARACTER OF THE SUITOR IN COURT ACCORDING TO CERVANTES, GUILLÉN DE CASTRO AND CRISTÓBAL SUÁREZ DE FIGUEROA}

\begin{abstract}
The tension between social class inertia and the new mobility of money economy is obvious in Spanish Golden Age literature. Hidalguía was in doubt, devalued and impoverished, according to Cervantes and other writers. In this context, Guillén de Castro presents, in El pretender con pobreza, the conflict, probably autobiographical, between the noble and honest soldier who hopes to be rewarded, in the traditional
\end{abstract}


fashion, for his merits, and not for his poor appearance and little money, as will happen in the age of pageantry and courtesy. In fact, the ending of that comedy is very immovilist and conservative, since the protagonist will be able to restore his social credit and be rewarded by the powerful. According to Castro, high nobility should rescue the worthy and courageous knights out of class solidarity, and the crown would have to redeem that impove rished knighthood from their ill fate. Cristóbal Suárez de Figueroa, much more pessimistic, does not even consider this expectation in Elpasajero, but, instead, expresses a harsh criticism of the nobility and misused power. The former is interested into the social aspects and the latter more into politics.

KEYWORDS: Nobility, hidalguía, social mobility, suitor, Cervantes, Guillén de Castro, Elpretender con pobreza, Cristóbal Suárez de Figueroa, Elpasajero.

El punto en común entre los escritores de nuestro título es el conocido drama socioeconómico de los hidalgos desclasados, que, después de una honrosa carrera militar, aguardaban un destino o un socorro en la corte. Esos pretendientes se afanaban por conseguir los puestos y premios que la política real les escamoteaba, al haber cedido la corona, desde comienzos de siglo, los cargos importantes de la administración a la alta aristocracia castellana, desmilitarizada y convertida progresivamente en oligarquía ${ }^{1}$.

A la altura de 1615, don Quijote afirma que «es grande la confusión que hay entre los linajes» ${ }^{2}$; y en otro pasaje clasifica a las gentes en cuatro especies ascendentes y descendentes, en una definición harto intuitiva de la movilidad social de la época:

Unos, que tuvieron principios humildes, y se fueron estendiendo y dilatando hasta llegar a una suma grandeza; otros, que tuvieron principios grandes, y los fueron conservando y los conservan y mantienen en el ser que comenzaron; otros, que, aunque tuvieron principios grandes, acabaron en punta, como pirámide, habiendo diminuido y aniquilado su principio hasta parar en nonada, como lo es la punta de la pirámide, que respeto de su basa o asiento no es nada; otros hay, y éstos son los más, que ni tuvieron principio bueno ni razonable medio, y así tendrán el fin, sin nombre, como el linaje de la gente plebeya y ordinaria ${ }^{3}$.

Como bien sabemos, esa novela sugiere irónicamente que el plebeyo Sancho, aunque nombrado por escarnio, resultará ser un honrado y ecuánime gobernador, y que su

\footnotetext{
${ }^{1}$ Véase, sobre todo, Maravall, Poder, honor y élites (Madrid: Siglo XXI, 1979) 2a parte, caps. 1 y 2.

${ }^{2}$ Cervantes, Miguel de, Don Quijote de la Mancha, dir. Francisco Rico (Barcelona: Crítica, 1998), II, 6, 675.

3 Ibidem.
} 
amo puede pasar por un dignísimo ejemplar de la nobleza natural, que emana de la verdadera virtud personal ${ }^{4}$.

Dentro del estamento noble había muchas calidades, que un observador tan perspicaz como el propio Caballero de la Triste Figura no podía por menos que percibir con claridad:

(...) No todos [los caballeros] son corteses ni bien mirados: algunos hay follones y descomedidos. Ni todos los que se llaman caballeros lo son de todo en todo: que unos son de oro, otros de alquimia, y todos parecen caballeros, pero no todos pueden estar al toque de la piedra de la verdad. Hombres bajos hay que revientan por parecer caballeros, y caballeros altos hay que parece que aposta mueren por parecer hombres bajos; aquéllos se levantan o con la ambición o con la virtud, éstos se abajan o con la flojedad o con el vicio; y es menester aprovecharnos del conocimiento discreto para distinguir estas dos maneras de caballeros, tan parecidos en los nombres y tan distantes en las acciones 5 .

Con todo, cierta holgura económica era condición indispensable para ostentar nobleza en cualquier grado: Domínguez Ortiz habló en 1998 de una «contaminación de los valores estamentales por los dinerarios» ${ }^{6}$; Maravall asentó que «la riqueza, por debajo, era la eficaz palanca para el éxito» ${ }^{7}$ y más modernamente, Domingo Carvajal ha afirmado que «el factor desencadenante de la escala nobiliaria es de tipo puramente económico» ${ }^{8}$. De modo que, en el fondo, la herramienta más útil para el ascenso social era el dinero, a pesar de su escaso prestigio teórico ${ }^{9}$. Aunque esa idea era de muy vieja data, muchos autores áureos la repetirán, como Góngora, en su célebre letrilla «Dineros son calidad», de hacia 1601:

Dineros son calidad, jverdad! (...)

Cruzados hacen cruzados, escudos pintan escudos, y tahúres, muy desnudos, con dados ganan Condados; ducados dejan Ducados, y coronas Majestad: jverdad! (... $)^{10}$.

${ }^{4}$ Comp., para la movilidad social, Maravall, Estado moderno y mentalidad social (siglos XV al XVII) (Madrid: Revista de Occidente, 1972), 412-419.

${ }^{5}$ Cervantes, Miguel de, Don Quijote de la Mancha, II, 6, 674.

${ }^{6}$ «La España del Quijote», en Miguel de Cervantes, Don Quijote de la Mancha, I, lxxxvii-civ, xcv.

${ }^{7}$ La literatura picaresca desde la bistoria social (siglos XVI y XVII) (Madrid: Taurus, 1986), 419.

${ }^{8}$ Tipologia de los personajes en la dramaturgia de Guillén de Castro y Bellvís (1569-1631), (Tesis Doctoral: Universidad de Barcelona, junio de 2005), 618.

${ }^{9}$ Comp. las notas de Domínguez Ortiz, en la edición que manejamos de Don Quijote de la Mancha, I, xcii-xciv.

${ }^{10}$ Góngora, Luis de, Letrillas, ed. Robert Jammes (Madrid: Castalia, 1987), nº XVIII, 93. En realidad, el Arcipreste de Hita ya había resumido justamente esa idea en su «Enxienplo de la propiedat qu'el 
De modo que la posición socioeconómica de una familia en la corte obedecía a una complicada casuística, según anota modernamente Pérez León:

Todo ello dio lugar a una estructura social compleja y dinámica en la que la prosperidad económica, una exitosa carrera administrativa o el aprovechamiento de las redes de relación verticales (patronazgo-clientelismo) y horizontales (paisanaje, parentesco, de negocios) serían factores decisivos en el estatus de las personas. De igual manera, la presencia de la aristocracia cortesana espoleó las aspiraciones sociales entre la población madrileña, igualmente deseosa de reconocimiento y éxito social. Estrategias convencionales como la obtención de ejecutorias de hidalguía en las Chancillerías o la compra de privilegios de hidalguía, hábitos de órdenes militares y títulos nobiliarios o el gasto suntuario, tan habituales entre los grupos en ascenso, se complementarían con otras, mucho más sutiles y extendidas entre amplios sectores de la población. En la capital, una de estas estrategias de promoción social sería la solicitud de admisión como hidalgo en Madrid ${ }^{11}$.

Las pretensiones y deseos de los personajes literarios son muchos: ocultar la miseria; sustentarse dignamente después de una carrera militar; ser honrado, no ser menos, medrar o ser más, ostentar honra, pasar por hidalgos, caballeros o nobles, sustentar nobleza, pretender dádivas o cargos, instalarse en la burocracia...

En definitiva, en la sociedad áurea convivían de forma inextricable el valor hereditario de la sangre y el creciente poder del dinero. Por un lado, la riqueza era el complemento necesario de la nobleza y, por otro, se preferían las rentas y los títulos a las actividades económicas como tales, propias de la burguesía. De modo que incluso las gentes adineradas deseaban pasar antes por nobles que por simplemente ricas, y el tránsito desde el grupo de los llamados poderosos o parvenus hacia el poder y la nobleza era relativamente fácil, porque el dinero allanaba el camino ${ }^{12}$.

Recordemos que, aunque el afán de casi todos los españoles era asimilarse a la nobleza, ésta se defendía en virtud del principio de cierre estamental descrito por Maravall ${ }^{13}$. No en vano, por ejemplo, quedó sin efecto real el plan del Conde-Duque de Olivares de conceder honras proporcionadas a los estratos humildes; tampoco tuvo consecuencias su objeción a que la aristocracia copase los altos puestos de la

dinero ha», en un dístico como «sea un hombre nesçio e rudo labrador, / los dineros les fazen hidalgo e sabidor» o en el verso «el que non ha dineros non es de sí señor» Juan Ruiz, Libro de buen amor (Madrid: Cátedra, 1992), estr. 491, 129.

11 «Sociedad de la villa y corte: hidalgos en el Madrid de Carlos IV», Historia y genealogía, 5 (2015): 267292, 267. Domínguez Ortiz historió, entre otras cuestiones, las falsas ejecutorias de nobleza, que permitían igualar ficticiamente a los descendientes de conversos con los aristócratas, o incluso superarlos en limpieza de sangre (en diversos trabajos, pero sobre todo en La clase social de los conversos de Castilla [Granada: Universidad, 1991]). Contreras, Soria Mesa, Pérez León y otros han explorado las manipulaciones genealógicas en la Edad Moderna, mientras que Egido repasó en su día las numerosas sátiras sobre linajes.

12 Véase Salazar Rincón, El mundo social del "Quijote” (Madrid: Gredos, 1986) cap. V.

13 Poder, honor y élites, 80. 
administración ${ }^{14}$. Numerosos personajes literarios lamentan precisamente ese inmovilismo, como cuando la mujer de Sancho Panza exclama: «No, sino estaos siempre en un ser, sin crecer ni menguar, como figura de paramento! $\rangle^{15}$; aunque su marido también se precia de tener «cuatro dedos de enjundia de cristianos viejos»" con la típica aspiración a ser más de muchos cristianos rancios simplemente por el hecho de saberse tales.

La comedia lopesca se funda, en gran medida, en esas expectativas sociales, con un abundante muestrario de conflictos y promociones inter-estamentales. Por acudir a un ejemplo menos conocido, pero muy elocuente, Con su pan se lo coma escenifica el debate de los dos hermanos protagonistas, Fabio y Celio, entre el inmovilismo y el dinamismo social. Mientras el primero sigue el consejo paterno de vivir «sin salir de nuestro nido / y conservar llanamente / el estado en que nacimos» (vv. 1007-1009), su hermano aduce:

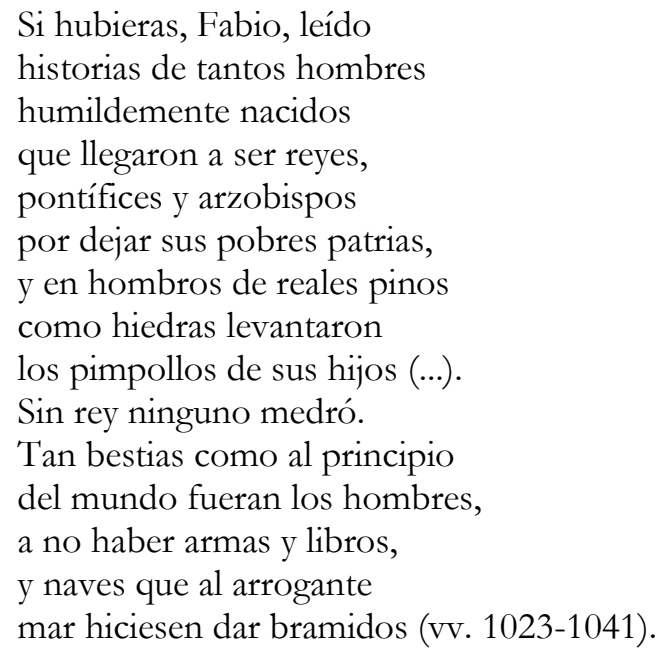

Sin embargo, frente a esos ricos propietarios rurales plebeyos tentados (o no) por la corte del Fénix de los Ingenios, el grupo de los hidalgos estaba en una crisis irreversible, repudiado por la aristocracia y abocado a caer en el estado llano. La imagen del hidalgo depauperado y desclasado era ya un lugar común, tanto en la realidad histórica como en la literatura del Siglo de Oro, en particular la de signo realista o satírico $^{17}$. Esta cuestión ha sido analizada por numerosos historiadores; así, Llorens explicó en su día:

${ }^{14}$ Comp. González Alonso, «El Conde Duque de Olivares y la administración de su tiempo», Anuario de historia del derecho español, 59 (1989): 5-48, 13.

${ }_{15}$ Cervantes, Miguel de, Don Quijote de la Mancha, II, 5, 667.

16 Ibidem, II, 4, 661.

${ }^{17}$ Véase la nota complementaria a Don Quijote, II, 583, n. 985.35, con bibliografía; y también, entre otros muchos trabajos, Salazar Rincón, El mundo (cap. II), y Rodríguez Mansilla «El hidalgo pobre en la poesía satírico-burlesca de Alonso de Castillo Solórzano» (Donaires Del Parnaso, I, Núms. 48 y 49)», Calípe, 24.1 (2019): 78-100. 
(...) Mal podría sobrevivir el hidalgo. Imposible convertirse en un soldado mercenario; al fin y al cabo pertenecía a la nobleza. La misma razón le impedía trabajar como un plebeyo en la agricultura ni en el «trato» o comercio. Cerrados estos caminos, el hidalgo -si no emigraba a América- consumiría su tiempo llamando sin gran resultado a las puertas de los nobles, o arrastrando vida vegetativa en pequeños lugares donde al menos poseía una casa y algunas tierras ${ }^{18}$.

$\mathrm{Y}$, cuando esos recursos se acababan, sólo restaba emigrar a la corte u otras grandes ciudades para pasar desapercibido o encontrar un acomodo, como el hidalgo lazarillesco o el don Toribio del Buscón ${ }^{19}$. Cervantes también define, a su modo, esta coyuntura en la Segunda parte del ingenioso caballero don Quijote de 1615 como una segunda pobreza -frente a la miseria de índole moral- y como un problema de honra espantadiza, es decir, de hidalguía o caballería dudosas:

«(...) Pero tú, segunda pobreza, que eres de la que yo hablo, ¿por qué quieres estrellarte con los hidalgos y bien nacidos más que con la otra gente? ¿Por qué los obligas a dar pantalia a los zapatos, y a que los botones de sus ropillas unos sean de seda, otros de cerdas, y otros de vidro? ¿Por qué sus cuellos, por la mayor parte, han de ser siempre escarolados, y no abiertos con molde?» $\mathrm{Y}$ en esto se echará de ver que es antiguo el uso del almidón y de los cuellos abiertos. Y prosiguió: «iMiserable del bien nacido que va dando pistos a su honra, comiendo mal y a puerta cerrada, haciendo hipócrita al palillo de dientes con que sale a la calle después de no haber comido cosa que le obligue a limpiárselos! ¡Miserable de aquel, digo, que tiene la honra espantadiza, y piensa que desde una legua se le descubre el remiendo del zapato, el trasudor del sombrero, la hilaza del herreruelo y el hambre de su estómago!» ${ }^{20}$.

Algunos de ellos ni siquiera tenían bienes negociables, al menos según las fuentes literarias: el hidalgo toledano de Lazarillo de Tormes no posee muebles ni paga el alquiler; el propio don Quijote apenas conserva unas tierras poco productivas, malvendidas para comprar libros de caballería; el don Toribio del Buscón no tiene, literalmente, dónde caerse muerto, y el avariento don Marcos de El castigo de la miseria de María de Zayas únicamente cuenta con «una pobre cama» sobre la que duerme y come $^{21}$.

La hidalguía, según se ha estudiado profusamente, estaba en entredicho, devaluada y empobrecida. La Corona empezó a exigirles tributos y los pecheros aspiraban a ella, en una frontera difusa que permitía a muchos plebeyos arrogarse cierta

18 «Don Quijote y la decadencia del hidalgo», Aspectos sociales de la literatura española (Madrid: Castalia, 1974): 47-66, 58.

${ }^{19} \mathrm{El}$ segundo explica que «un mayorazgo roído, como él, en un pueblo corto olía mal a dos días y no se podía sustentar, y que por eso iba a la patria común adonde caben todos y adonde hay mesas francas para estómagos aventureros», es decir, la corte (II, 5, 143-144).

${ }^{20}$ Cervantes, Miguel de, Don Quijote de la Mancha, II, 44, 985.

${ }^{21}$ Zayas y Sotomayor, María de, El castigo de la miseria, Novelas amorosas y ejemplares, Julián Olivares (Madrid, Cátedra, 2000), 253. 
nobleza, promocionarse socialmente a través de las letras, como Tomás rodaja, el Licenciado Vidriera, o incluso -a causa de la debilidad económica de la monarquíapor medio de la compra de hidalguías y cargos municipales ${ }^{22}$. Y, a la inversa, para los hidalgos y caballeros legítimos, cualquier probanza o pleito requerían una inversión económica ${ }^{23}$.

La frontera entre la alta y la baja nobleza y los hidalgos y los caballeros quedaría definida así: "Los títulos y caballeros supieron adaptarse a estos cambios y aprovechar las ocasiones de lucro que los nuevos tiempos ofrecían, adueñándose de los cargos de mayor relieve en la corte, el ejército y la administración. Los hidalgos, por el contrario, tuvieron que resignarse a arrastrar una existencia monótona, insípida y asediada por la pobreza» ${ }^{24}$.

Este es el caso, naturalmente, del Cervantes histórico, «hijo de un hidalgo de nueva ejecutoria acostumbrado al hambre y a las deudas» ${ }^{25} \mathrm{y}$ del hidalgo Alonso Quijano, diseccionado en los primeros párrafos de esa novela ${ }^{26}$. La condición de hidalgo auténtico de éste último va unida a la estrechez económica y a las dudas sugeridas irónicamente por Cervantes- sobre una posible mancha morisca por su origen geográfico. Ese protagonista será después acusado por su sobrina de hacerse pasar por caballero «no lo siendo; porque, aunque lo puedan ser los hidalgos, no lo son los pobres $»^{27}$, un juicio inapelable que alcanzará al protagonista de la pieza de Guillén de Castro que después comentaré. La pobreza y el desclasamiento también serán el sino del inolvidable Filipo de Carrizales, descrito sumariamente al comienzo de El celoso extremeño:

No ha muchos años que de un lugar de Estremadura salió un hidalgo, nacido de padres nobles, el cual, como un otro Pródigo, por diversas partes de España, Italia y Flandes anduvo gastando así los años como la hacienda; $y$, al fin de muchas peregrinaciones, muertos ya sus padres y gastado su patrimonio, vino a parar a la gran ciudad de Sevilla, donde halló ocasión muy bastante para acabar de consumir lo poco que le quedaba. Viéndose, pues, tan falto de dineros, y aun no con muchos amigos, se acogió al remedio a que otros muchos perdidos en aquella ciudad se acogen, que es el pasarse a las Indias (...) (325-326).

${ }^{22}$ Maravall redujo ese fenómeno a «una parte mínima, estadísticamente irrelevante, que muy poco afectaba a la estructura social» (Poder, honor, $1^{a}$ parte, apartado G, 90-91).

${ }^{23}$ De nuevo, Góngora lo dejó advertido en su citada letrilla: «Cualquiera que pleitos trata, / aunque sean sin razón, / deje el río Marañón, / y entre el río de la Plata, / que hallará corriente grata / y puerto de claridad: / jverdad.» (96).

${ }^{24}$ Salazar Rincón, El mundo, 102.

25 Ibidem, 103.

${ }^{26}$ Otros pasajes reveladores son el de II, 2, en el que don Quijote se defiende de la acusación de haberse atribuido el don y «arremetido a caballero» siendo uno «de aquellos hidalgos escuderiles que dan humo a los zapatos y toman los puntos de las medias negras con seda verde» (643-644); o el de las medias descosidas de don Quijote, que da pie a unas reflexiones de Cide Hamete, intercaladas con comentarios del narrador, sobre la sufrida pobreza material de los «hidalgos y bien nacidos» (II, 53, 984985). Para el problema del don y la usurpación de apellidos, veáse Maravall, La literatura picaresca, 535; y sobre la frontera entre hidalgos y caballeros, Salazar Rincón, El mundo, 90.

${ }^{27}$ Cervantes, Miguel de, Don Quijote de la Mancha, II, 6, 674. 
Pero mientras Carrizales granjeaba una enorme fortuna en Perú, muchos hidalgüelos paupérrimos malvivían como escuderos y pajes en las casas nobles de Madrid, hasta el punto de que la dudosa posición social del hidalgo pobre del XVII colindaba sospechosamente con la de los innumerables criados, menesterosos y marginados contemporáneos, como el pícaro plebeyo con tufos de nobleza y el hidalgo apicarado de las novelas de Cervantes, Quevedo, Salas Barbadillo o María de Zayas. El caso más llamativo es el de esos hidalgos que malviven en las ciudades, desde el desventurado hidalgo toledano de Lazarillo de Tormes hasta los famosos hidalgos chanflones del Buscón (II, 6) o el don Marcos de El castigo de la miseria de Zayas, entre otros $^{28}$. Vicente Espinel aclaró al comienzo de Marcos de Obregón que su intención era «mostrar en mis infortunios, y adversidades, cuánto importa a los escuderos pobres, o poco hacendados, saber romper por las dificultades del mundo, y oponer el pecho a los peligros del tiempo y la fortuna, para conservar con honra y reputación un don tan precioso como la vida» ${ }^{29}$.

La novela picaresca puso de manifiesto la existencia de un confuso inframundo de desclasados y de arribistas sin escrúpulos que llegaron a blasonar irónicamente incluso de su prosapia picaresca. Lázaro de Tormes, Guzmán de Alfarache, el Buscón don Pablos y otros personajillos aspiraban a un medro bastardo, impropio y sin verdaderos méritos, a base de engaños y mentiras ${ }^{30}$. O, simplemente, como apuntan Cervantes y otros con más o menos ambigüedad, la vida picaril seduce a todos: el citado Marcos de Obregón coquetea con el hampa sevillana a pesar de ser un caballero oriundo de Ronda; más anecdóticamente, el Guitón Onofre se apellida justamente Caballero; comparece incluso en algunas Novelas ejemplares cervantinas la figura del estudiante de buena cuna y familia adinerada que prefiere (por una temporada) desgarrarse de su familia y entregarse a la vida picaresca antes de volver a la universidad o a su casa, un tipo descrito tanto en La gitanilla o La ilustre fregona ${ }^{31}$ como en el primer Quijote (cap. 44).

Bastantes comedias se ocuparon también, aunque con notas menos sensacionalistas y ridículas, de los nobles empobrecidos que intentaban parecer ricos

\footnotetext{
${ }^{28}$ La novela quevediana merecería ser ampliamente citada aquí, pero bastará con tres pinceladas: don Toribio, un hidalgo con apellidos campanudos, aclara que ha enajenado incluso su sepultura y que «sólo el don me ha quedado por vender, y soy tan desgraciado que no hallo nadie con necesidad dél, pues quien no le tiene por ante le tiene por postre, como el remendón, azadón, pendón, blandón, bordón y otros así», en alusión a la universalización del don nobiliario (II, 5, 143); y el capítulo siguiente, tantas veces citado, contendrá un verdadero decálogo de supervivencia para los «caballeros hebenes»o «güeros, chanflones, chirles, traspillados y caninos» (144).

${ }^{29}$ Espinel, Vicente, Relaciones de la vida del escudero Marcos de Obregón, La novela picaresca española, ed. Florencio Sevilla (Madrid: Castalia, 2001), 671.

${ }^{30}$ El Buscón, por ejemplo, en el colmo de la perversión genealógica, niega su estirpe auténtica y alberga infundados pensamientos de caballero: en II, 2 explica su plan social (113) y, a la altura de II, 5, ruega a su tío Alonso, verdugo: «No pregunte por mí ni me nombre, porque me importa negar la sangre que tenemos» (141), rompiendo toda relación con los suyos para emprender un camino fallido de falsa honra y de mentida caballería.

${ }^{31}$ Salazar Rincón analiza esas situaciones (El mundo, 99-101).
} 
para llamar la atención de sus damas, como en El caballero del milagro de Lope o en Hombre pobre todo es trazas de Calderón (1637), por ejemplo. El Fénix de los Ingenios incursionó repetidamente en estos temas: el motivo general del desclasamiento y la irrelevancia social de la nobleza tronada por falta de caudal es central en las primeras escenas de Dineros son calidad de Lope de Vega, donde el arruinado conde Federico se duele de su infortunio en versos de gran patetismo. Aquel diálogo merece recordarse, pues la duquesa Julia aconseja a ese noble que rehaga su fortuna para volver a ser quien fue, «pues veis que solo en el mundo / dineros son calidad», provocando la indignación de los empobrecidos hijos del conde (3). La familia tratará de rehabilitarse socialmente rehaciendo su fortuna por distintos medios. La pobreza estimada presenta el dilema femenino entre un pretendiente rico y otro pobre; Las flores de don Juan, El halcón de Federico, El triunfo de la humildad y, naturalmente, la acción en prosa autobiográfica La Dorotea vuelven sobre el tema del galán pobre, pero digno de amor, una idea obsesiva que debió quedarle al Fénix de sus años juveniles y, sobre todo, de la ruptura traumática con Elena Osorio. Los ejemplos de otros dramaturgos podrían multiplicarse, pero bastará con dos: Cada loco con su tema de Antonio Hurtado de Mendoza ofrece un curso acelerado de hidalguía, con varios ejemplos de tipos hidalgos, y El alcalde de Zalamea de Calderón presenta al ridículo don Mendo, prototipo de noble famélico que esconde su hambre ${ }^{32}$.

Ese noble tronado o ese pobre con pujos de nobleza solía ser tenaz en su lucha por mantenerse a flote o promocionarse socialmente. El primer camino, bastante arduo, era servir a un señor, confiando en que, legítimamente y poco a poco, uno podría «valer más, siendo humilde, conquistando con eso voluntades», según afirma, por ejemplo, Castillo Solórzano en El bachiller Trapaza $a^{33}$. Este asunto, junto con la presión mercantilista y dineraria, está detrás del gracioso debate entre Sancho Panza y su señor sobre si éste debe recibir un salario o bien servir a merced, a la espera de dádivas señoriales, como sus colegas de los libros de caballería, «que cuando menos se lo pensaban, si a sus señores les había corrido bien la suerte, se hallaban premiados con una ínsula, o con otra cosa equivalente, y, por lo menos, quedaban con título y señoría» ${ }^{34}$.

El axioma popular «Iglesia, mar o casa real» es bien conocido ${ }^{35}$. Los estudios y el ejército eran dos medios francos para mantener o aumentar la posición social. Así

${ }^{32}$ La relación entre comedia y dinero ha sido estudiada por diversos especialistas en un volumen monográfico de actas coordinado por Pedraza Jiménez et al., El dinero y la comedia española. XXXVII Jornadas de teatro clásico, Almagro, 10, 11 y 12 de julio de 2014 (Ciudad Real: Ediciones de Castilla-La Mancha, 2016).

33 Castillo Solórzano, Alonso de, Aventuras del Bachiller Trapaz̧a, ed. Jacques Joset (Madrid: Cátedra, 1988), 86.

${ }^{34}$ Cervantes, Miguel de, Don Quijote de la Mancha, II, 7, 681. Véase Domínguez Ortiz («La España del Quijote», en Miguel de Cervantes, Don Quijote de la Mancha [Barcelona: Crítica, 1998] I, lxxxvii-civ, xciv) y Maravall (La literatura picaresca, cap. V).

${ }^{35}$ Véanse los importantes matices del citado Domínguez Ortiz a esa trascendental frasecilla; en síntesis, ese historiador distinguió varios niveles: la carrera eclesiástica; el ejército; el comercio marítimo, con los armadores, los cargadores y el corso; la universidad, que franqueaba el camino a la burocracia estatal; los oficios de palacio («La España del Quijote», xcvi-xcviii). 
lo explica don Quijote al ama y la sobrina: «Dos caminos hay, hijas, por donde pueden ir los hombres a llegar a ser ricos y honrados: el uno es el de las letras; otro, el de las armas. Yo tengo más armas que letras $(. .).\rangle^{36}$. Lope, todavía más práctico, anotará otros tres factores de progreso en la ya citada Con su pan se lo coma: armas, libros y naves (vv. 1039-1040). Con los libros aludía, naturalmente, a los estudios universitarios en los dos Derechos, que franqueaban el paso al clero, al gobierno y a la burocracia. Tal era la afinidad entre las letras y la administración, que Sancho Panza llega a su ínsula vestido «a lo letrado», aún sin serlo ${ }^{37}$.

En efecto, una y otra vez comprobamos en la literatura que la baja nobleza, los plebeyos con posibles y hasta algunos pícaros acudían a la universidad: en El bachiller Trapaza se nos aclara, por ejemplo, que dos caballeros mejicanos condiscípulos del protagonista aspiraban a sendas becas de los colegios mayores «para que de allí ascendiesen a más superiores puestos ${ }^{38}$. Sin embargo, esos pícaros fracasan en ese medio para el ascenso social, lo que no deja de subrayar su importancia: así, Guzmán de Alfarache no concluirá su carrera de teología en Salamanca y mientras el abuelo de Trapaza le aconseja estudiar en esa misma ciudad para «valer por vuestro ingenio»y porque «hemos visto levantadas casas por las letras» ${ }^{39}$, su nieto no le hará caso e intentará darse un lindo verde de caballería en esa universidad como un verdadero intruso, mediante el juego y la superchería social, muy al estilo picaresco ${ }^{40}$.

Otro vehículo de promoción era la pretensión, la forma más moderna y burocrática de la tradicional dádiva o merced del poderoso. Los pretendientes confluían en la corte, según Pérez León:

La villa de Madrid, centro neurálgico de la monarquía hispánica, se convirtió a lo largo de la Edad Moderna en el destino transitorio o permanente de muchas personas vinculadas de una forma u otra a la corte y al aparato de la administración regia. A los servidores de la Casa Real y la nobleza cortesana hay que sumar toda una pléyade de burócratas, hombres de letras, militares y, por supuesto, una multitud de pretendientes a mercedes y $\operatorname{cargos}^{41}$.

El galán de la membrilla de Lope presenta al rancio y arruinado hidalgo don Félix, que enamora a la hija del rico labrador Tello. Éste sólo accede a entregársela si el galán logra un hábito y unas rentas del rey. Tirso, en Don Gil de las calzas verdes, hace que el gracioso Caramanchel describa así, entre sus muchos amos anteriores, a un abogado:

Acomodéme después con un abogado que es de las bolsas abogado, y enfadóme que, aguardando

${ }^{36}$ Cervantes, Miguel de, Don Quijote de la Mancha, II, 6, 676.

${ }^{37}$ Ibidem, 44, 981.

${ }^{38}$ Castillo Solórzano, Alonso de, Aventuras del Bachiller Trapaz̨a, cap. 2, 73.

39 Ibidem, cap. 1, 68-69.

${ }^{40} \mathrm{Ibidem}$, cap. 2.

${ }^{41}$ «Sociedad de la villa $y$ corte», 267. 
mil pleiteantes que viese

sus procesos, se estuviese

catorce horas enrizando

el bigotismo (...) (vv. 412-419).

Y poco después, la misma doña Juana, travestida en el don Gil de la obra, se fingirá pretendiente forastero: «Vengo a pretender aquí / un hábito o encomienda»; a lo que Caramanchel replica sarcásticamente: «¿A pretender entráis mozo? / Saldréis viejo» (vv. 497-502). Ya en la jornada II don Martín explica que «Vine a cierta pretensión / a Madrid, que el rey confirme» (vv. 1474-1475). Fuego de Dios en el querer bien de Calderón trae al pleiteante don Juan de Toledo y a su padre, que espera a la flota de Indias con el fruto de un jugoso cargo. Ambos quedarán chasqueados y sumidos en un infierno legal por la pérdida de las naos.

Los cargos oficiales eran, en verdad, muy lucrativos y codiciados, hasta por los plebeyos. El caso más extremo es el de Sancho Panza, descrito como un pretendiente un tanto iluso e inconsistente por el ama de don Quijote: «(...) no entraréis acá, saco de maldades y costal de malicias. Id a gobernar vuestra casa y a labrar vuestros pegujares, y dejaos de pretender ínsulas ni ínsulos ${ }^{42}$; y él se defiende diciendo que aspira a "gobernar y regir mejor que cuatro ciudades y que cuatro alcaldes de corte»" Conforme avance la novela, Sancho, su esposa y, por supuesto, don Quijote, llegarán a creer posible que ese escudero logre ser gobernador, o incluso rey, en virtud de una merced sobrevenida, a pesar de su plebeyez e ignorancia ${ }^{44}$.

La vida militar se asociaba tópicamente con la nobleza: Cervantes, exsoldado él mismo, observó, por ejemplo, en su Novela de la señora Cordelia, que «el ejercicio de las armas, aunque arma y dice bien a todos, principalmente asienta y dice mejor en los bien nacidos y de ilustre sangre ${ }^{45}$; y lo anota justamente a propósito de dos caballeros principales que dejan sus estudios en Salamanca para ir a la guerra de Flandes, aunque finalmente vuelvan a la universidad en Bolonia, presumiblemente durante la tregua de 1574-76. La literatura áurea está repleta de militares pobres o medianos, desde el codicioso Licenciado Peralta de El casamiento engañoso -que procede de una remota aldea- y el dicho soldado de La guarda cuidadosa, hasta los numerosos galanes combatientes o excombatientes de las comedias de Lope y otros dramaturgos, típicamente caballeros particulares que regresan de Flandes para caer en las redes del amor por alguna dama de la Corte ${ }^{46}$.

Aunque estaba ya en franca decadencia y se nutría sobre todo de mercenarios, la guerra resultaba una salida honrosa para nuestros hidalgos y caballeros arruinados y sin porvenir ${ }^{47}$. En este punto, el soldado andrajoso y celosísimo de La guarda cuidadosa, protesta expresivamente: «El hábito no hace al monje; y tanta honra tiene un soldado

\footnotetext{
${ }^{42}$ Cervantes, Miguel de, Don Quijote de la Mancha, II, 2, 640.

${ }^{43}$ Ibidem.

${ }^{44}$ Ibidem, II, caps. 4-5.

${ }^{45}$ Cervantes, Miguel de, Novelas ejemplares, ed. Jorge García López (Barcelona: Crítica, 2001), 481.

${ }^{46}$ Comp. García Hernán, La cultura de la guerra y el teatro del Siglo de Oro (Madrid: Sílex, 2007).

47 Véase Domínguez Ortiz, «La España del Quijote», xcvii-xcviii.
} 
roto por causa de la guerra, como la tiene un colegial con el manto hecho añicos, porque en él se muestra la antigüedad de sus estudios (...)» (938).

El tema soldadesco puede ir unido al motivo de la pretensión cortesana, sobre todo en la novela, pero también en otros géneros: muchos dignos hidalgos y caballeros pobres y provincianos se alistaban y bastantes de ellos terminaban como soldados rotos pretendientes, que, después de una carrera militar, aspiraban a recompensas o pensiones, al estilo de Miguel de Cervantes, por ejemplo ${ }^{48}$. El mismo soldado de La guarda cuidadosa expone al Sacristán, a un tiempo, sus pretensiones sobre la criada Cristinica y sobre su pobre soldadesca:

Que el otro día le envié un billete amoroso, escrito por lo menos en un revés de un memorial que di a Su Majestad, significándole mis servicios y mis necesidades presentes (que no cae en mengua el soldado que dice que es pobre), el cual memorial salió decretado y remitido al limosnero mayor; y, sin atender a que sin duda alguna me podía valer cuatro o seis reales, con liberalidad increíble y con desenfado notable, escribí en el revés dél (...) (937).

La ironía cervantina es aquí muy evidente, pues, aunque el desdichado mílite sea paupérrimo, exhibe tristemente sus patentes ante cualquiera y hasta usa el reverso de una de ellas para requebrar a la fregona. Después describirá su exagerado currículum al amo de la muchacha:

Pues lléguese vuesa merced a esta parte, y tome este envoltorio de papeles; y advierta que ahí dentro van las informaciones de mis servicios, con veinte y dos fees de veinte y dos generales, debajo de cuyos estandartes he servido, amén de otras treinta y cuatro de otros tantos maestres de campo, que se han dignado de honrarme con ellas (945).

Pues lo juzga una sólida base sobre la que asentará su petición de unos destinos: «(...) estoy consultado en uno de tres castillos y plazas, que están vacas en el reino de Nápoles; conviene a saber: Gaeta, Barleta y Rijobes» (ibídem); para insistir después, con su aplomo característico: «soldado soy, castellano pienso ser» (949). Finalmente, el rechazo de Cristina dará pie a las dos cancioncillas finales en las que el excombatiente se definirá tristemente como un «roto soldado lego» y el sacristán lo motejará de «pretendiente de Gaiferos» (951) ${ }^{49}$.

Guillén de Castro, dramaturgo inclinado a cierta comedia realista de costumbres matrimoniales -Los mal casados de Valencia, El curioso impertinente o El vicio en los extremos y algunas piezas de corte palatino, como El perfecto caballero-, se interesó también por el marido buscavidas urbano -La verdad averiguada y engañoso casamiento- $\mathrm{y}$ finalmente por la nobleza desclasada y pobre, como en La bumildad soberbia y, sobre

48 García Lorenzo estudió a los pobres soldados pretendientes, tan bien descritos por Cervantes y otros, en sus trabajos de 1981 y 1982.

49 Tampoco es imposible encontrar soldados pretendientes supuestos o fingidos, como cuando, al final de El bachiller Trapaza, el protagonista, para cortejar a una aristócrata, se hará pasar por un noble militar portugués que pretende un gobierno en Brasil (cap. XVI). 
todo en El pretender con pobreza. Ésta última, fechada en 1620-24 y publicada en 1625, ha sido clasificada por Antonucci como una típica comedia urbana de ese autor ${ }^{50}$. Se trata de un drama de costumbres con un protagonista empobrecido, el caballero aragonés don Juan de Urrea, un exsoldado en Italia y Flandes que llega a la Corte a pretender recompensas del rey y los grandes de la nobleza, aunque éstos, a su vez, lo esquivarán hasta que una dama lo socorra, logre presentarse con el decoro que corresponde a su posición y reciba las ansiadas mercedes ${ }^{51}$.

Castillejo resumió así el tema general de la obra: «El frustrante intento de ser atendido por una burocracia cerrada»; y su trama: «Esta obra muestra la angustia de una persona tímida, pobre y de mal vestir, al presentar memoriales y tener que insistir [en] que la burocracia lo atienda $»^{52}$. Y finalmente, ofreció un certero juicio crítico: «Pese a un final algo débil, es una pieza importante por la claridad con que expone este problema social ${ }^{53}$. Domingo Carvajal también ha comentado el trance de Urrea:

Triste correspondencia riqueza-honor que, en cualquier caso (...), le sirve a Guillén para, de forma indirecta, defender encarecidamente la igualdad esencial de todos los nobles (...), justo cuando la política centralizadora de Felipe III había empezado a cuestionarla con su promoción de la alta aristocracia castellana en los puestos principales de la administración del estado. Ya se ha comentado la doble discriminación que, en virtud de su origen provinciano y de su pertenencia a las capas bajas de la aristocracia, obligó a Guillén a emigrar a la Corte en busca de un mecenas entre la gran nobleza castellana. Experiencia personal que se dejará sentir en la radicalidad de los discursos de tantos y tantos caballeros arruinados que proclamarán la igualdad de todos los bien nacidos ${ }^{5}$.

La primera escena ya nos muestra al duque en plena tertulia palaciega sobre comedias -con un amistoso elogio de Lope-, deudas de juego y paseos cortesanos. El noble recibe de mala gana al heroico soldado, que sufre con paciencia la descortesía, aunque se enzarzará después con la servidumbre del duque.

Así pues, nuestro protagonista es un caballero aragonés que se precia de su honra, aunque, según él, sea ésta precisamente la causa de su ruina:

Llámome don Juan de Urrea, cuyo apellido y blasón

por lo mejor de Aragón

en toda España campea;

50 «Géneros dramáticos y comicidad en el teatro de Guillén de Castro», en Le radici spagnole del teatro moderno europeo. Atti del Convegno di studi (Napoli, $15-16$ maggio 2003), eds. Gerardo Grossi y Augusto Guarino (Mercato San Severino: Edizioni del Paguro, 2004), 101-116, 109.

${ }^{51}$ En otro lugar he repasado la raíz autobiográfica de muchas de las ideas expuestas en El pretender con pobreza. Véanse también, sobre esa cuestión, los trabajos de Domingo Carvajal y Oleza.

${ }^{52}$ Castillejo, David, Guía de las ochocientas comedias del Siglo de Oro (Madrid: Ars Millenii, 2002), 251.

${ }^{53}$ Ibidem, 268.

${ }^{54}$ Domingo Carvajal, Gemma, Tipología de los personajes en la dramaturgia de Guillén de Castro y Bellvís (1569-1631), (Tesis Doctoral: Universidad de Barcelona, junio de 2005), 619. 
y yo no he desmerecido

la nobleza que he heredado,

pues de puro ser honrado,

dejo de ser lo que he sido ${ }^{55}$.

Y después insistirá en el valor de su sangre, con dos componentes, el propio y el allegado o adquirido:

(...) No soy tan poco, que no sea bien nacido, tanto como bien criado, con un valor heredado, y otro valor adquirido ${ }^{56}$.

Mientras, en otro pasaje, resumirá su vida y prosapia:

Fueron ricos mis abuelos, mas, porque yo no lo fuera, mis padres pródigamente distribuyeron su hacienda. Murieron dentro de un año los dos, cuando yo a mi cuenta llegaría a diez y seis ${ }^{57}$.

Es decir, a causa de sus antepasados, que hicieron gala de la característica generosidad de la nobleza, Urrea quedó en la miseria y sin perspectivas sociales, en una situación que María de Zayas definiría unas décadas después en pocas palabras, al describir a su don Marcos de El castigo de la miseria: «(...) un hidalgo, tan alto de pensamientos como humilde de bienes de fortuna» ${ }^{58}$.

De manera que el empobrecido don Juan abandonó su patria chica y se enroló como soldado:

Quedé con brío y pobreza tan repugnantes entonces, que obligaron mi paciencia a no emplear en la paz los valores de la guerra. Salime de Zaragoza, y para luzir mis prendas, vendí las que me quedauan

55 Castro, Guillén de, El pretender con pobreza, Segunda parte de las comedias de don Guillén de Castro (Valencia, Miguel Sorolla, 1625), 338. Modernizo levemente el texto original desde el punto de vista fonológico.

${ }^{56}$ Castro, Guillén de, El pretender con pobreza, 339.

${ }^{57}$ Ibidem, 345.

58 Zayas y Sotomayor, María de, El castigo de la miseria, 253. 
de mi limitada herencia ${ }^{59}$.

Como muchos caballeros de la época, necesita salir de su entorno para hacer méritos y encontrar un acomodo, aunque no parece huir de la miseria vergonzante de otros personajes literarios, o al menos, su creador, acaso por solidaridad de clase o por decoro teatral, no lo dibuja con ese tremendismo, aunque anota algunos detalles de su pobre atuendo.

Después añadirá Urrea sus seis años como sargento mayor del tercio ${ }^{60}$, pues ya hemos visto que la milicia era un modo de aquilatar la nobleza, además de un porvenir honroso para los hidalgos y los nobles empobrecidos.

Pero lo que más nos importa es la pretensión de nuestro personaje de recibir mercedes en Palacio, una vez licenciado:

Llegué a esta Corte con bríos

de que en mí fueran premiados

servicios de mis pasados,

aunque bastaran los míos ${ }^{61}$.

Sin embargo, durante buena parte de la pieza don Juan no logrará ese propósito y seguirá quejándose de su desdicha, a saber: que carece de medios para sustentar su posición social y autorizar así sus pretensiones, en una época en la que la nobleza se medía por la ostentación y el lujo. Lejos de cualquier afán suntuario, Urrea se avergüenza de sus ropas raídas y encaja aproximadamente en el tipo del hidalgo tal y como lo ha descrito Salazar Rincón:

Pero lo que convierte al hidalgo en una figura ridícula, y a la vez conmovedora, no es la penuria de su casa ni la bolsa vacía, sino la presunción, el disimulo y los ademanes de gran señor, con que trata de disfrazar los agujeros de las medias, el remiendo del zapato o el hambre del estómago. La vida del hidalgo pobre se convierte así en una pálida imitación, ridícula caricatura casi siempre, del lujo y las formas de vida ostentosa de los caballeros y títulos ${ }^{62}$.

Sus menguados recursos lo llevan a un lamentable pretender con pobreza, como él mismo proclama obsesivamente:

¡A qué estremos mi pobreza me ha traído! ¿Qué deshonras!

Con pobreza pretendí

mercedes de un Rey, y sordas

hallé en todos las orejas;

sólo me faltaba agora

${ }^{59}$ Castro, Guillén de, El pretender con pobreza, 345.

${ }^{60}$ Ibídem, 346.

${ }^{61}$ Ibidem, 338.

${ }^{62}$ Salazar Rincón, El mundo, 104. 


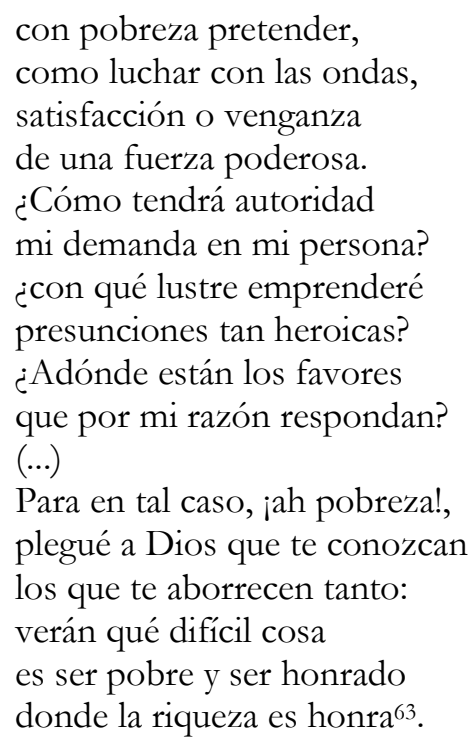

Y tampoco echemos en saco roto el final del lamento de Urrea: «donde la riqueza es honra» (ibidem), que resume justamente el trágico -para él- predominio de la fortuna sobre otras consideraciones como el honor y la sangre.

Cotaldo, su criado, también resume el dilema de Urrea axiomáticamente: «en la Corte es cosa dura / con pobreza el pretender ${ }^{64}$. Y ese mismo criado anota algunos rasgos, entre satíricos y melancólicos:

$$
\begin{aligned}
& \text { Señor no tienes razón, } \\
& \text { perdóname, aunque lo diga: } \\
& \text { cuando tus pobres vestidos } \\
& \text { desmienten tus hidalguías, } \\
& \text { culpa a tu poca fortuna, } \\
& \text { y no a las agenas vistas. } \\
& \text { Si vas con esas vayetas } \\
& \text { tan fin lustre y tan sin tinta, } \\
& \text { que azulean (y en un pobre } \\
& \text { parece que significan } \\
& \text { celos de los bien vestidos), } \\
& \text { ¿cómo ha de ser conocida } \\
& \text { tu persona, y respetada, } \\
& \text { si ya no te determinas } \\
& \text { de letra grande a ponerte } \\
& \text { como redoma en botica, } \\
& \text { un rótulo en las espaldas } \\
& \text { que tus calidades diga; } \\
& \text { por eso el ponerse al pecho }
\end{aligned}
$$

${ }^{63}$ Castro, Guillén de, El pretender con pobreza, 369.

${ }^{64}$ Ibidem, 352. 
un hábito, es cosa linda,

aunque en una mala capa,

hasta la cruz va corrida,

como falso juramento,

y aun plegue a Dios que no digan ${ }^{65}$.

Recordemos, de paso, el dicho de que la necesidad tiene cara de hereje, corriente en el Siglo de Oro e ilustrado por Góngora en otra estrofa de su letrilla ya citada:

No hay persona que hablar deje

al necesitado en plaza;

todo el mundo le es mordaza

aunque él por señas se queje;

que tiene cara de hereje,

y aun fe la necesidad:

jverdad! 66.

Pues bien: a pesar de su indigencia, cuando el conde ofrece a Urrea un puesto de escudero o mayordomo en su palacio, éste pide poder servir de incógnito porque, según él, las hidalguías «tan mayores de la marca / que su sangre purifican» no deben rebajarse «a serviles sujeciones» ${ }^{67}$. Por una parte, Urrea se disgusta con motivo, puesto que escudero era precisamente el nombre que se daba a los más pobres nobles sin título ${ }^{68}$; por otra, el ofendido mensajero replicará con desprecio que hay otros muchos caballeros mejores que él para esos empleos y ambos sacarán las espadas. El enfado de Urrea procede también de la puntillosidad del caballero tradicional ante las ofensas, estudiada por Caro Baroja (1968). En cualquier caso, nuestro caballero se aleja del servilismo y de la conducta pulida del cortesano moderno ${ }^{69}$.

Covarrubias, en su Tesoro, apostilló que «en la paz, los escuderos sirven a los señores de acompañar delante sus personas, asistir en la antecámara o sala; otros se están en sus casas y llevan acostamiento de los señores, acudiendo a sus obligaciones a tiempos ciertos. Hoy día más se sirven dellos las señoras; y los que tienen alguna pasada, huelgan más de estar en sus casas que de servir, por lo poco que medran y lo mucho que les ocupan» (s. v. escudero). El citado Marcos de Obregón explica que, dado que se halla «desacomodado al cabo de mi vejez»y para que no lo prendan por «vagamundo», será contratado como «escudero y ayo» del doctor Sagredo y su esposa ${ }^{70}$.

${ }^{65}$ Ibidem, 342.

${ }^{66}$ Góngora, Luis de, Letrillas, no XVIII, 95. Comp. Alemán, Guæmán de Alfarache, II, 1, y vol. II, 263 y n. 4.

${ }^{67}$ Castro, Guillén de, El pretender con pobreza, 343.

68 Véase Salazar Rincón (El mundo, 89).

${ }^{69}$ Maravall citó dos pasajes del Discurso de todos los diablos y del Buscón donde Quevedo aclaraba las ventajas de mostrarse servil y adulador con los superiores (La literatura picaresca, 384-385). El mismo historiador ilustró en otra parte las nociones de la inflación de honores y del honor comunicado o proyectado (en este caso, del amo noble al criado con ínfulas) (Poder, honor y élites, 41-42).

${ }^{70}$ Espinel, Vicente, Relaciones de la vida del escudero Marcos de Obregón, 672. 
Pero la degradación social corría pareja con la precariedad económica y muchos hidalgos y caballeros pobres terminaban como simples pajes o gentilhombres: así, el puesto del mencionado don Marcos de El castigo de la miseria, conllevaba «los usados atributos, picardía, porquería, sarna y miseria» ${ }^{71}$.

La capacidad objetiva de un caballero como don Juan para ser sirviente de un señor noble fue también resumida por Herrero García:

Ello daba lugar a que paralelamente al servicio doméstico plebeyo se constituyese un servicio doméstico hidalgo, cerrado en sí mismo a través de un completo escalafón y cuyos rangos inferiores tan solo se diferenciaban de los criados ordinarios en sus pujos nobiliarios y en su función principalmente ornamental $^{72}$.

En otra parte los define como «un Estado Mayor de personas graves», compuesto por mayordomos, camareros, maestresalas, caballerizos y los indispensables secretarios ${ }^{73}$. Estos personajes se daban mucha importancia socialmente, según corrobora Suárez de Figueroa en su Pasajero: «Los criados de mayor jerarquía son los más difíciles de sobrellevar, por ser sin número sus impertinencias, sus demasías» ${ }^{74}$. En la pieza de Guillén de Castro vemos, sin ir más lejos, cómo el mayordomo del conde se propasa con el digno Urrea.

La segunda jornada de nuestra comedia nos brinda una escena impagable, cuando los pretendientes esperan a un consejero de guerra en el patio de los Consejos del Alcázar viejo. Mientras todos entregan sus memoriales, don Juan es ignorado por su atuendo, pues, como él mismo resume, «el vestido / hace dudoso el linaje» (ibidem). La cruel moraleja es que un tal don Íñigo será premiado injustamente con una patente de capitán, a pesar de haber sido un bufón cobarde en la guerra, es decir, exactamente lo contrario de nuestro protagonista ${ }^{75}$.

Ya en el tercer acto, su amada doña Inés lo socorrerá y Urrea podrá presentarse decorosamente ante su benefactor, que accederá a sus peticiones. Su criado Cotaldo comenta entonces con amarga ironía:

(...) Ayer porque azuleauan vayetas que le cubrían, mirándole, no le vían; y hallándole, no le hablauan: y hoy, porque ya sin

${ }^{71}$ Zayas y Sotomayor, María de, El castigo de la miseria, Novelas amorosas y ejemplares, 253.

72 Oficios populares en la sociedad de Lope de Vega (Madrid: Castalia, 1977), 31.

73 Ibidem, 28-29.

${ }^{74}$ Suárez de Figueroa, Cristóbal, Elpasajero, ed. Ma Isabel López Bascuñana (Barcelona, PPU, 1988), I, 147. Y el mismo caso podía darse entre las antiguas señoras, como en La señora Cornelia de Cervantes, donde encontramos a una orgullosa ama de una buena familia, los Crivelli, que ha terminado sirviendo a la noble protagonista: «pues con ser quien soy, he terminado siendo masara de españoles» (505), un detalle que da lugar a un expresivo discurso sobre este fenómeno social (503-505).

${ }^{75}$ Castro, Guillén de, El pretender con pobreza, 349. 
el viejo ropaje, luzido está,

su parecer se verá

con su nombre en el consejo ${ }^{76}$.

Finalmente, el rey le concederá el puesto de maese de campo del Tercio de Sicilia, con hábito y encomienda, y podrá casarse felizmente.

Por vía de contraste, frente al valeroso Urrea, Cristóbal Suárez de Figueroa renegará de la nobleza ${ }^{77}$ y retratará en Elpasajero al mal pretendiente:

Cuanto lo primero, siendo idiota, se publica por doctísimo. Todo lo sabe, sobre todo habla con desentonada voz, lleno siempre de confusión y temeridad. Con esta misma confianza que pratica en las conversaciones se introduce en la pretensión. Osa pintarse de admirables colores. Asiste, ruega, adula, corteja, sufre malos semblantes, peores respuestas, descortesías del criado, menosprecios del señor, naciendo todo esto de ser poco circunspecto y menos sensitivo. Muchos acompañan la paciencia con la importunación, y no espantándoles el no, aunque le repitan salen con todo, y más si ambos medios se convierten en desvergüenza, instrumento que tanto corre por el mundo. En suma, los que siguen este camino allanan dificultades, vencen rebeldías y no inclinan, sino violentan a condescender con sus disinios. Así el defetuoso consigue lo instituido para el benemérito ${ }^{78}$.

Igual de curiosa es su observación de que muchos aspiraban a lograr sus peticiones sobre el especioso argumento de que sus abuelos o sus padres ya ejercían y poseían esos cargos y mercedes ${ }^{79}$. Suárez presentará también a un soldado que «iba al reino de Nápoles con mediano sueldo, efecto más de favores que de servicios» ${ }^{80}$. Se despachará a gusto sobre los ascensos, cuando explica que el mal pretendiente aspira, como poco, a la plaza de general ${ }^{81}$. Y en otro pasaje enumerará los cargos y dignidades concretos que se pedían: «Ni se avergüenzan cuando, sin algún mérito, cansan, importunan, muelen por el hábito, por la encomienda, por la llave, por cubrirse y por otras dignidades de presidencias y consejos» ${ }^{82}$.

Suárez dedicará otro vibrante párrafo al nefasto político, una vez que está en el ejercicio del cargo:

Sale, pues, éste de la corte, y siendo incapacísimo para todo, descubre ser sólo hábil en vicios, en hurtos, en excesos, en atropellar honras, en cometer injusticias, sirviendo de escándalo a la infeliz ciudad o villa que le ha de sufrir tres años. Al fin, da la vuelta glorioso de su buena administración, y con el fruto de los robos inquiere sendas, interpone medios, alega servicios, y sin omisión, internándose siempre más, logra sus diligencias, por la vía que le ofrece la ocasión, antes el demonio. Con dos o tres oficios

\footnotetext{
${ }^{76}$ Ibidem, 361.

77 Por ejemplo, en I, 187, 204, y II, 397-400.

${ }^{78}$ Suárez de Figueroa, Cristóbal, El pasajero, I, 124.

${ }^{79}$ Ibidem, II, 399.

${ }^{80}$ Ibidem, I, 58.

${ }^{81}$ Ibídem, II, 399.

82 Ibidem.
} 
queda ya éste por ladrón confirmado, por pésimo sin remedio. ¿Puede haber mayor infortunio que ser los súbditos gobernados por los peores?_(...). Si la iglesia no juzga de lo oculto, ¿qué mucho que los ministros seglares remitan a papeles la suficiencia del pretensor? Presenta, pues, los suyos nuestro querido y exagera en ellos sus desvelos, sus cuidados. Atrévese a representar partes y letras; y cuando el mundo le tiene más olvidado, o en menos estimación, se aparece entre nubes para proceder como siempres3.

Todo ello contrasta con la literatura áulica de la época y con los famosos consejos quijotescos a Sancho antes de su gobierno, entre los que el buen caballero condena, por ejemplo, la «ley del encaje» ${ }^{84}$.

$\mathrm{Y}$, a la inversa, Suárez anota sobre el buen aspirante, mucho menos afortunado y mucho más parecido a Urrea:

Hace primero caudal, de costumbres, de estudios, de experiencia. Trata de entablarse poco a poco, juzgando la aceleración madrastra del buen consejo. Detienen de continuo sus propuestas recelos de no enfadar. Da poco lugar al oficio de la lengua (...), juzgando tener tal vez el silencio no menor artificio que la elocuencia (...). Siempre corto, siempre recatado, apenas mueve la lengua para quejarse, oprimido de propias desconfianzas. Muerénsele las palabras en la boca al tratar de sí. Aflígele el imaginado desvío del paje, la compuesta altivez del ministro, y, remitiendo la diligencia de un día para otro, hace difícil su empresa apenas visto, cuanto más conocido. Por tan cuerda remisión, por tan prudente enfrenamiento dejan de ser colocados donde merecen muchos que fueran felicidad de sus repúblicas y gloria de sus mismas patrias. Colegiréis, pues, de lo referido haber en el mundo sobra del benemérito si les diesen lugar los indignos; si no usurpasen los malos los asientos de los buenos ${ }^{85}$.

Resumirá Suárez esa general injusticia en pocas frases, de sabor alemaniano: «El caso es que cada uno juega para sí. No hay valor, no hay esfuerzo, no hay aliento ni determinación para cosa buena. Todo es flojedad, todo remisión, todo propio interés, sin celo de bien común ni apetencia de futura gloria y fama» ${ }^{86}$.

En el fondo, Suárez concuerda con Urrea en su pesimismo sobre los escasos progresos profesionales que solían hacer muchos pajes y criados de casas nobles, que apenas podían jubilarse como gentilhombres de silla o simples porteros, en otro camino social cerrado ${ }^{87}$. Incluso se lamenta acerca de la masa de sirvientes y cortesanos indignos: «En todo viven engañados los príncipes, ceñidos siempre de brutos, de lisonjeros, de truhanes» ${ }^{88}$; a la vez que ensalza como «requisitos de felicidad» el «no ver

${ }^{83}$ Ibidem, I, 124-125.

${ }^{84}$ Cervantes, Miguel de, Don Quijote de la Mancha, II, 42, 971.

${ }^{85}$ Suárez de Figueroa, Cristóbal, El pasajero, I, 125. En Castiglione, El cortesano, IV, cap. 4 (esp. 321 322), ya se comentaban estas cuestiones políticas.

${ }^{86}$ Suárez de Figueroa, Cristóbal, El pasajero, II, 401.

${ }^{87}$ Ibidem.

${ }^{88}$ Ibidem, I, 159-160. 
la corte, no servir, librarse de tribunales» ${ }^{89}$, una perspectiva que, claro está, debería desengañar al pobre don Juan.

Suárez se queja de quienes esquivan la vida militar desde su comodidad cortesana, sobre un mullido lecho o arrellanados en los cojines de su carruaje ${ }^{90}$. Este binomio corte-guerra está también presente en el capítulo sexto del segundo Quijote, donde el protagonista opone a los caballeros cortesanos, que viven una vida cómoda, y a los andantes como él, expuestos a los azares y las inclemencias ${ }^{91}$. Lope, en piezas como Con su pan se lo coma y El villano en su rincón, pondrá en solfa la cortesanía y encarará al mismísimo rey con la nobleza natural de los labradores ricos. En la primera el monarca llega a proclamar durante su estancia en el campo: «Hoy quiero ser labrador» (v. 1072); y en la segunda será justamente el rico propietario Juan Labrador quién se piense rey en su rincón frente al rey mismo, intrigado y algo ofendido. El mensaje anticortesano quedará claro al final de Con su pan, cuando los labradores vuelvan a su predio, ennoblecidos por el soberano ${ }^{92}$. A fin de cuentas, se trata de visiones sublimadas, muy distintas de la realidad de la capital, llena de pobres y aventureros que seguían la llamada ley ecológica urbana del pícaro y el pobre, enunciada por Maravall ${ }^{93}$.

En síntesis, el desprecio de casta se palpa en El pasajero: «iOh, turba vil de nobles, sujeta por antojos, por vanagloria, a servidumbre, a menosprecio!» ${ }^{94}$. Suárez, como muchos de sus contemporáneos, se encuentra en una encrucijada, pues reniega por igual de los nobles desclasados y del moderno valor social del dinero ${ }^{95}$. El valenciano, en cambio, no denigra a toda la nobleza, sino que enaltece al digno y humilde caballero empobrecido y critica veladamente a los titulados soberbios y de vida muelle, que parecen haber olvidado el temple guerrero de la verdadera aristocracia, representada por el valiente Urrea.

Nuestros dos autores asisten a un fin de época y se asoman a un panorama desolador sin la debida perspectiva, confundiendo las causas y los efectos, los males y sus síntomas. Históricamente hablando, hoy sabemos que quienes podían reconducir la situación no supieron o no quisieron hacerlo. Los titulados coparon los puestos de la administración y se olvidaron del drama de sus inferiores, les negaron los socorros que necesitaban o incluso se aprovecharon de ellos, subempleándolos en menesteres humillantes.

La tensión entre la inercia social y la movilidad propia de la economía dineraria es palmaria en ambos autores. En ese ambiente enrarecido, Guillén de Castro presenta el conflicto, un tanto autobiográfico, del exsoldado linajudo y honrado que espera ser valorado, al estilo tradicional, por sus merecimientos, y no por su pobre apariencia y escaso peculio, como sucederá en el siglo del boato y la cortesanía. En realidad, la solución de esa pieza será harto inmovilista y conservadora, puesto que el hidalgo

${ }^{89}$ Ibídem, I, 208-209.

${ }^{90}$ Ibidem, II, 399.

${ }^{91}$ Cervantes, Miguel de, Don Quijote de la Mancha, 672.

${ }_{92}$ Para este tema, véase Salomon, Lo villano en el teatro del Siglo de Oro (Madrid: Castalia, 1985).

${ }^{93}$ La literatura picaresca, cap. XIV.

${ }^{94}$ Suárez de Figueroa, Cristóbal, Elpasajero, I, 159.

95 Ibidem, I, 326. 
protagonista logrará restaurar su crédito social y recibirá la debida recompensa de los poderosos. Según Guillén de Castro, la alta nobleza debería rescatar por solidaridad estamental a los caballeros dignos y valerosos, y la corona tendría que redimir a esa caballería depauperada de su triste destino. Se trata lógicamente de una mera ilusión o de un deseo, pero Castro los presenta como una posibilidad teatral tangible al final de la obra.

Suárez, mucho más pesimista, ni siquiera toma en consideración ese camino. En el fondo, nuestros escritores exponen ideas muy distintas a propósito de la nobleza histórica: Urrea propugna la solidaridad entre los nobles al margen de su nivel económico. Suárez se manifiesta como un enemigo de esa clase en varios pasajes de su libro, e insiste en las ideas del mérito personal y el esfuerzo, acercándose a Cervantes, que igualaba la nobleza natural con la virtud. Castro aporta la nostalgia del noble tronado y Suárez una dura crítica a la nobleza y al poder mal ejercido. El primero se interesa más por la vertiente social y el segundo más por la política.

Finalmente, el tono de los dos escritores difiere: don Guillén pinta su tipo social con tintes casi costumbristas, con la simpatía de quien ha pasado por parecidas estrecheces y sin caer en la sátira, pues ni siquiera el gracioso Cotaldo se extralimita demasiado en sus burlas; Suárez presenta un repertorio de quejas amargas y una dura requisitoria social, una suerte de doble enmienda a la totalidad contra los peores pretendientes y la nobleza. Castro confía en las mercedes llovidas, aunque requieran el decoro del candidato. Ambos reniegan del criterio con que se las concede, que ven como totalmente arbitrario, subrayando las dádivas injustas a personajes dudosos. 


\section{REFERENCIAS BIBLIOGRÁFICAS:}

Alemán, Mateo, Guzmán de Alfarache, ed. José Mª Micó, (Madrid: Cátedra, 1987).

Antonucci, Fausta, «Géneros dramáticos y comicidad en el teatro de Guillén de Castro», en Le radici spagnole del teatro moderno europeo. Atti del Convegno di studi (Napoli, 15-16 maggio 2003), eds. Gerardo Grossi y Augusto Guarino (Mercato San Severino: Edizioni del Paguro, 2004), 101-116.

Caro Baroja, Julio, «Honor y vergüenza: examen histórico de varios conflictos», en J. G. Peristiany, ed., El concepto del honor en la sociedad mediterránea (Barcelona: Labor, 1968), 77-126.

Castiglione, Baltasar de, El cortesano, ed. Rogelio Reyes Cano (Madrid: Espasa, 1984).

Castillejo, David, Guía de las ochocientas comedias del Siglo de Oro (Madrid: Ars Millenii, 2002).

Castillo Solórzano, Alonso de, Aventuras del Bachiller Trapaza, ed. Jacques Joset (Madrid: Cátedra, 1988).

Castro, Guillén de, La bumildad soberbia, Cervantesvirtual, http://www.cervantesvirtual.com/obra-visor/la-humildad-soberbia--

0/html/dcb4ecd6-2dc6-11e2-b417-000475f5bda5 2.html\#I 0 (consultado el 9 de diciembre de 2019).

-----, Obras completas, ed. Joan Oleza (Madrid: Fundación J. A. Castro-Akal, 1997).

-----. El pretender con pobreza, Segunda parte de las comedias de don Guillén de Castro (Valencia: Miguel Sorolla, 1625), 335-374.

Cervantes, Miguel de, Don Quijote de la Mancha, dir. Francisco Rico (Barcelona: Crítica, 1998).

-----, Novelas ejemplares, ed. Jorge García López (Barcelona: Crítica, 2001).

Chauchadis, Claude, Honneur, morale et sociêté dans I'Espagne de Philippe II (París: CNRS, 1984).

Contreras Contreras, Jaime, «Linajes y cambio social: la manipulación de la memoria», Historia Social, 21 (1995): 105-124. 
Courtney Bruerton, «The Chronology of the Comedies of Guillén de Castro», Hispanic Review, XII.2 (1944): 89-151.

Díez Borque, José Ma Sociedady teatro en la España de Lope de Vega (Barcelona: A. Bosch, 1978).

Domingo Carvajal, Gemma, Tipología de los personajes en la dramaturgia de Guillén de Castro y Bellvís (1569-1631), (Tesis Doctoral: Universidad de Barcelona, junio de 2005).

Domínguez Ortiz, Antonio, La clase social de los conversos de Castilla en la Edad Moderna (Granada: Universidad, 1991 [1955]).

-----, La sociedad española en el siglo XVII (Madrid: CSIC, 1964).

-----, El Antiguo Régimen: los Reyes Católicos y los Austrias (Madrid: Alfaguara, 1976).

-----, «La España del Quijote», en Miguel de Cervantes, Don Quijote de la Mancha, dir. Francisco Rico (Barcelona: Crítica, 1998, I) lxxxvii-civ.

Egido, Aurora, «Linajes de burlas en el Siglo de Oro», Studia Áurea. Actas del III Congreso de la AISO, I (Toulouse-Pamplona: 1996), 19-50.

Espinel, Vicente, Relaciones de la vida del escudero Marcos de Obregón, La novela picaresca española, ed. Florencio Sevilla (Madrid: Castalia, 2001), 665-772.

Faliu-Lacourt, Christiane, Un dramaturge espagnol du Siècle d'Or. Guillén de Castro (Toulouse: Université de Toulouse-Le Mirail, 1989).

García Hernán, David, La cultura de la guerra y el teatro del Siglo de Oro (Madrid: Sílex, 2007).

García Lorenzo, Luciano, «Prólogo», Don Quijote de la Mancha de Guillén de Castro (Madrid: Anaya, 1971).

-----, «Quevedo y sus soldados pretendientes», Homenaje a Quevedo, ed. Víctor García de la Concha (Salamanca: Universidad de Salamanca, 1982 [1996]) 347-354.

-----, El teatro de Guillén de Castro (Barcelona: Planeta, 1976).

-----, «La tragedia del desengaño: el soldado pretendiente en el teatro español del Siglo de Oro», en Teoría y realidad en el teatro español del siglo XVII. La influencia italiana, ed. F. Ramos (Roma: Instituto Español de Cultura, 1981), 183-193.

Góngora, Luis de, Letrillas, ed. Robert Jammes (Madrid: Castalia, 1987). 
González Alonso, Benjamín, «El Conde Duque de Olivares y la administración de su tiempo», Anuario de historia del derecho español, 59 (1989): 5-48.

Green, Otis H., «New Documents for the Biography of Guillén de Castro y Bellvís», Revue Hispanique, LXXXI (1933): 248-260.

Herrero García, Miguel, Oficios populares en la sociedad de Lope de Vega (Madrid: Castalia, 1977).

Insúa, Mariela; Schmelzer, Felix K. E., eds., Teatro y poder en el Siglo de Oro (Pamplona: Servicio de Publicaciones de la Universidad de Navarra, 2013), 199-213.

Juliá Martínez, Eduardo, ed. Obras de Don Guillén de Castro y Bellvís (Madrid: Real Academia Española, 1925-1927).

Jutglar, Antoni, La España que no pudo ser (Barcelona: Dopesa, 1971).

Llorens, Vicente, «Don Quijote y la decadencia del hidalgo», Aspectos sociales de la literatura española (Madrid: Castalia, 1974), 47-66.

Maire Bobes, Jesús, «Los villanos ambiciosos del teatro renacentista», Archivum, 46-47 (1996-1997): 289-302.

Maravall, José Antonio, Estado moderno y mentalidad social (siglos XV al XVII) (Madrid: Revista de Occidente, 1972).

-----, Poder, honor y élites en el siglo XVII (Madrid: Siglo XXI, 1979).

-----, La literatura picaresca desde la historia social (siglos XVIy XVII) (Madrid: Taurus, 1986).

----, Teatro y literatura en la sociedad barroca (Barcelona: Crítica, 1990 [1972]).

-----, La cultura del Barroco (Barcelona: Ariel, 1998 [1975]).

Moreno de Vargas, Bernabé, Discursos de la nobleza de España (Madrid: María de Quiñones, 1636).

Oleza, Joan, «Introducción», Guillén de Castro. Obras completas (Madrid: Fundación J. A. Castro-Akal, 1997, vol. I) i-xxxv.

Pedraza Jiménez, Felipe B., González Cañal, Rafael, y Marcello, Elena E., eds., El dinero y la comedia española. XXXVII Jornadas de teatro clásico, Almagro, 10, 11 y 12 de julio de 2014 (Ciudad Real: Ediciones de Castilla-La Mancha, 2016). 
Pérez, Joseph, «Réflexions sur l’hidalguía», «Hidalgos» \& «Hidalguia» dans l'Espagne des XWXVW siécles, Théories, pratiques et représentations (París: CNRS, 1989).

Pérez León, Jorge, «Sociedad de la villa y corte: hidalgos en el Madrid de Carlos IV», Historia y genealogia, 5 (2015): 267-292.

Peristiany, J. G., ed., El concepto del honor en la sociedad mediterránea (Barcelona: Labor, 1968).

Pitt-Rivers, Julian, «Honor y categoría social», en Peristiany, J. G., ed., El concepto del honor en la sociedad mediterránea (Barcelona: Labor, 1968), 21-76.

Quevedo, Francisco de, La vida del Buscón, ed. Fernando Cabo (Barcelona: Crítica, 1993).

Ramos, Juan Luis, "Guillén de Castro en el proceso de la Comedia barroca», en Cuadernos de Filología, III. 3 (1983): 169-198.

-----, «Guillén de Castro en la comedia barroca», en Joan Oleza, ed., Teatro y prácticas escénicas, II: la Comedia (Londres: Tamesis Books, 1986), 229-248.

Rodríguez Mansilla, Fernando, «El hidalgo pobre en la poesía satírico-burlesca de Alonso de Castillo Solórzano» (Donaires Del Parnaso, I, Núms. 48 y 49)», Calíope, 24.1 (2019): 78-100.

Ruiz, Juan, Libro de buen amor, ed. Alberto Blecua (Madrid: Cátedra, 1992).

Salazar Rincón, Javier, El mundo social del "Quijote" (Madrid: Gredos, 1986).

Salomon, Noël, Lo villano en el teatro del Siglo de Oro (Madrid: Castalia, 1985).

Sanz Ayán, Carmen, «Poderosos y privilegiados», José Alcalá-Zamora y Queipo de Llano, coord., La vida cotidiana en la España de Velázquez. (Madrid: Temas de Hoy, 1995), 149-168.

Soria Mesa, Enrique, «Genealogía y poder. Invención del pasado y ascenso social en la España moderna», Estudis. Revista de Historia Moderna, 30 (2004): 21-55.

Suárez de Figueroa, Cristóbal, El pasajero, ed. $\mathrm{M}^{\mathrm{a}}$ Isabel López Bascuñana (Barcelona: PPU, 1988). 
Tirso de Molina, Don Gil de las calzas verdes, ed. digital Griso, Cervantesvirtual, http://www.cervantesvirtual.com/nd/ark:/59851/bmcr21b7 (consultada el 9 de agosto de 2020).

Vega, Félix Lope de, Con su pan se lo coma, https://artelope.uv.es/biblioteca/textosAL/AL0561 ConSuPanSeLoComa.p hp

-----, Dineros son calidad, Alicante, Biblioteca Virtual Miguel de Cervantes, 2011, http://www.cervantesvirtual.com/nd/ark:/59851/bmc377v0 (consultada el 30 de septiembre de 2020).

Wilson, William E., Guillén de Castro (Nueva York: Twayne Publishers, Inc., 1973).

Zayas y Sotomayor, María de, El castigo de la miseria, Novelas amorosas y ejemplares, Julián Olivares (Madrid: Cátedra, 2000), 253-293.

Recibido: 15 de octubre de 2020

Aprobado: 20 de octubre de 2020 